\title{
The Influence of Psychological Distance and Personal Relationship of Channel Members on Conflict, Satisfaction and Performance
}

\author{
Yicheng Liu $^{1}$ \\ ${ }^{1}$ Department of Marketing, School of Economic and Management, Tsinghua University, Beijing, China \\ Correspondence: Liu Yicheng, Room 105B, Building \#15, Zijing Apartment, Tsinghua University, Haidian District, \\ 100084, Beijing, China. Tel: 86-151-0105-5677.
}

Received: October 6, 2016

Accepted: October 18, 2016

Online Published: October 24, 2016

doi:10.5430/bmr.v5n4p14

URL: http://dx.doi.org/10.5430/bmr.v5n4p14

\begin{abstract}
This study aims to find out the influence of psychological distance and personal relationship of channel members on conflict, satisfaction and performance. And we also study the connection between psychological distance and personal relationship and the influence of personal relationship on organizational trust. Besides, we discuss the substitution effect of personal relationship to organizational relationship, in the specific business environment of China, especially in the cooperation between small distributors and large suppliers. The trust on the salesmen of suppliers from the dealers may have more influence on their decision and behaviors than the trust on the supply organization. So the influence of organizational trust may not be very significant in our study. Our data are from 200 gas stations of Sinopec. And we design panel data regressions of several dimensions for every research variable, to study it objectively and comprehensively. Based on the results of regressions, this study try to explain the effect of psychological distance and personal relationship on the factors of channel, and put forward some advice to company operation. The conclusion of our study may be different from many traditional theories, because we find that the organizational trust doesn't affect conflict, satisfaction and performance significantly.
\end{abstract}

Keywords: Channel members, Psychological distance, Personal relationship, Conflict, Satisfaction, Performance, Organizational trust

\section{Introduction}

We mainly discuss the different factors that will influence conflict, satisfaction and performance in channel. The most important two factors are psychological distance (Federico de Gregorio, Yunjae Cheong, \& Kihan Kim, 2012) and personal relationship (Don Y. Lee \& Philip L. Dawes, 2005), each can also be divided into several elements.

What's more, we test the influence of organizational trust on channel relation (Stephen A. Samaha, Robert W. Palmatier, \& Rajiv P. Dant, 2011, Keith G. Provan \& Steven J. Skinner, 1989), because this factor is usually considered as a significant one. However, our result may challenge the previous conclusions. And we will explain the reason in our research, based on the particularity of China's business environment and traditional culture (Don Y. Lee \& Philip L. Dawes, 2005).

Besides, the factors have interactive effect as well. For example, psychological distance has positive effect on personal relationship and personal relationship has positive effect on organizational trust. Those are also exciting discovery in our study, which will be mentioned later.

We also find out the different effect of every element of personal relationship. For instance, the willingness of trust may be more powerful than the behavior of trust, about affecting the trust relationship. The reason might be that the willingness can reflect the sense of trust better than the behavior of trust. (Robert M. Morgan \& Shelby D. Hunt, 1994)

After conclude the results of all the tests and examine all the hypotheses, we come up with some implications for the application area, which will be useful to the distributors and suppliers.

We have organized the remainder of this article as follows.

Part 1: An introduction for this paper.

Part 2: This part provides a literature review and the research background. 
Part 3: This part describes the hypotheses.

Part 4: In this section, the researcher explains the data analyses and the results of tests.

Part 5: Here the researcher summarizes the paper and comes up with some implications and shortages.

Part 6: Some references.

\section{Literature Review}

Conflict: A lot of literature talked about the conflict and performance in channel, most of the views believe that internal conflict will affect performance. This effect may be positive or negative, depending on the origin of conflict. (Bert Rosenbloom, 1973)

There are two kinds of conflict in channel, calling constructive conflict and destructive conflict. Constructive conflict will have positive influence on performance, because the members of channel may try to find out a way to solve problems. On the contrary, destructive conflict will have negative effect on performance, because members will bring personal dispute into work, which may reduce the work efficiency. The factors that influence conflict are centralization, formalization, internal volatility, team spirit and psychology distance. Psychology distance is usually the differences of values and way of thinking between channel members. The members who have a long psychology distance will be easier to conflict with each other. Those who have a close psychology distance will get along with each other better, which will lead to less conflict and higher performance. (Federico de Gregorio, Yunjae Cheong, \& Kihan Kim, 2012)

Conflict can be defined as either perceived differences on perspectives that can impede goals between parties (Gaski and Nevin, 1985) or perceived experiences describing psychological states about the relationship (Dant et al., 2006). Conflicts can arise from many areas in the relationship, including differences regarding priorities, time perspectives, and forms of earning (Garg and Rasheed, 2006; Shane and Cable, 1997). Consequently, differences on fundamental issues or perceptions about relationships are unlikely to be quickly resolved, leading to heated disputes, and creating destructive or dysfunctional conflict. Dysfunctional, enduring conflict can increase distractions, obstruct goal alignment, reduce synergy between partners (Anderson and Narus, 1990; Gaski, 1984), threaten the survival of the relationship (Grünhagen and Dorsch, 2003), and lead to costly litigation for both parties. Due to the delicate balance between franchisor control and franchisee autonomy, franchise success is strongly determined by the ability of the franchisor to manage conflict arising from the balance between the parties (Fulop and Forward, 1997).

Trust: Trust can be defined as franchisee confidence in accepting a calculated level of risk with the franchisor (Coleman, 1990), allowing franchisees to cope with vulnerability in their relationships with their franchisors. This calculation of trust is based on criteria of trustworthiness. Previous models of trust in channels research have identified competency and integrity as potential criteria (Davies and Prince, 2005; Dickey et al., 2007; Mayer et al., 1995).

Unfair in channel relationship will reduce organizational trust, leading to intensify of conflict and opportunism, which may influence the relationship and performance. The direct reason of conflict is lack of organizational trust, and conflict will reduce the performance. As a result, we can see that organizational trust will affect performance. (Stephen A. Samaha, Robert W. Palmatier, \& Rajiv P. Dant, 2011)

Trust will reduce dysfunctional conflict, but strengthen functional conflict. If we only consider the harmful conflict in channel relationship, then trust will have negative influence on conflict. In other word, good trust condition will lead to less dysfunctional conflict. (Graham R. Massey \& Philip L. Dawes, 2007)

The influence of organizational trust on performance is always a popular research topic. The relationship between distributors and suppliers will be affected by organizational trust to a great extent. When the organizational trust decrease, opportunism will increase. Using power to manage the relationship can ease the overt conflict, but the covert conflict and opportunism will still be unavoidable. In a word, organizational trust is quite important to both sides of channel. (Keith G. Provan \& Steven J. Skinner, 1989)

Some researchers summarize lots of views of organizational management theory. They analyze and test every kind of channel management method. Good organizational management can reduce conflict, improve satisfaction and performance. (Jan B. Heide, 1994)

Sometimes, the willingness of trust may be more powerful than the behavior of trust, about affecting the trust relationship. The reason might be that the willingness can reflect the sense of trust better than the behavior of trust. The behavior of trust is perhaps to maintain relationship, rather than to show their real trust from heart. In another word, it is easier to build a trust relationship when someone or some organizations have willingness of interaction of 
others. (Robert M. Morgan \& Shelby D. Hunt, 1994)

Excepting for the influence of organizational trust to conflict, satisfaction and performance, we can also see that personal relationship or personal trust is quite important. The effect of personal relationship will be extremely significant in the contact between the salesman of supplier and the distributor, especially in the situation of small distributors.

Personal relationship: Personal relationship and trust will have obvious effect on the cooperation of companies. China is a special country, because relationship of persons is more useful than organization relationship. Personal relationship will not only affect the channel connection, but also influence the organizational trust. The relation between the salesman of supplier and the distributor is easier to control and more practical. The premise of cooperation between suppliers and distributors is trust with each other, which is based on the personal relationship of boundary-spanners. In Chinese market, many decisions of purchase are made by the salesman, which means that the personal relationship will affect the business decisions and behaviors more significantly and efficiently. However, this kind of personal relationship can be a double-edged sword. For example, if one day the salesman leaves this company, he may also take away his customers. Unfortunately, in the special business environment of China, this is a risk which the suppliers have to take. (Don Y. Lee \& Philip L. Dawes, 2005)

The personal trust of distributors on the suppliers will be important to the compliance of them, affecting the channel conflict and performance. (Mark A.P. Davies, Walfried Lassar, Chris Manolis, Melvin Prince, \& Robert D. Winsor, 2011)

\section{Hypotheses}

Based on the literature above, we can see that previous research mainly focus on the effect of organizational trust in channel. However, there are little analyses and tests about the influence of psychological distance and personal relationship on conflict, satisfaction and performance in channel. Most of the description and study is just in theory. The existing literature only put forward that psychological distance and personal relationship will respectively affect channel relationship, but it never mentioned the question that how these two factors make a difference. What's more, it didn't consider the interactive relationship between psychological distance and personal relationship.

In our study, when we mention conflict, we only consider the dysfunctional conflict, which is harmful to the channel relationship. (Graham R. Massey \& Philip L. Dawes, 2007)

We want to focus on the effect of psychological distance and personal relationship on conflict, satisfaction and performance. Besides, we also use organizational trust to make this study more objective.

Psychological distance: From the previous literature, we can see that the psychological distance will have significant effect on conflict, satisfaction and performance. Psychological distance mostly refers to the differences of value and way of thinking between channel members. he members who have a long psychology distance will be easier to conflict with each other. Those who have a close psychology distance will get along with each other better, which will lead to less conflict and higher performance. In our study, we divide psychological distance into two factors, calling value and strategy. The strategy means the differences of the cognitive idea for the company strategy. (Federico de Gregorio, Yunjae Cheong, \& Kihan Kim, 2012)

Psychological distance may also be influential on the personal relationship, because people with similar value are easier to be good friends. And good personal relationship leads to better channel relation and operation performance, so psychological distance will have direct or indirect influence on channel relation and performance.

Based on the discussion above, we can have Hypothesis 1, Hypothesis 2a and Hypothesis 2b:

$\mathrm{H}_{1}$ : Psychological distance has positive effect on personal relationship. The closer the psychological distance is, the better the personal relationship will be.

$\mathrm{H}_{2 \mathrm{a}}$ : Psychological distance has negative effect on conflict. The closer the psychological distance is, the weaker the conflict will be.

$H_{2 b}$ : Psychological distance has positive effect on satisfaction and performance. The closer the psychological distance is, the higher the satisfaction and performance will be. Here the influence of psychological distance on performance is indirect.

Personal relationship: Personal relationship is a very typical factor in China's market, which will have a great influence on channel internal relationship. To study this factor, we choose the data from Sinopec and its 200 gas stations to do the research. As a huge supplier, Sinopec sends customer managers to communicate with their 
distributors, 200 gas stations. As a result, the personal relationship here mainly refers to the relation between customer managers and the distributors. (Don Y. Lee \& Philip L. Dawes, 2005)

Discussing personal relationship, we usually use two kinds of elements, calling the personal relation condition and the communication frequency.

Personal relation condition: The personal relation condition can be the connection situation, trust degree and private feeling. We can divide it into two factors, calling the fact of relationship and the willingness of contact. The personal relation condition is a qualitative assessment about the personal relationship.

Communication frequency: The communication frequency consists of the frequency of meeting and the frequency of calling. The frequency can measure the intimate level of channel members and make an accurate evaluation about the personal relationship quantitatively. (Robert M. Morgan \& Shelby D. Hunt, 1994)

The personal relationship should also be influential on organizational trust, especially in the situation of our research, in which customer managers are the most important bridges to both sides.

On the whole, personal relationship has direct regulating effect on conflict. And it also affects performance directly by strengthen the communication. Besides, the direct influence of personal relationship on conflict and performance will transfer into indirect influence of psychological distance, because the psychological distance has effect on personal relationship.

Personal relationship will have direct effect on satisfaction because it can improve the level of trust. However, the influence of psychological distance on satisfaction should be indirect. The two factors of psychological distance, calling value and strategy, will not improve channel relation or distribution fairness, so they cannot affect satisfaction directly. As a result, psychological distance will influence satisfaction indirectly, through the effect of personal relationship. People with close psychological distance will have better personal relationship, leading to higher channel satisfaction.

Based on the discussion above, we can have Hypothesis 3a and Hypothesis $3 \mathrm{~b}$ :

$\mathrm{H}_{3 \mathrm{a}}$ : Personal relationship has negative effect on conflict. The better the personal relationship is, the weaker the conflict will be.

$H_{3 b}$ : Personal relationship has positive effect on satisfaction and performance. The better the personal relationship is, the higher the satisfaction and performance will be.

Many researchers emphasize the importance of organizational trust on conflict, satisfaction and performance. However, the cooperation of Sinopec and gas stations is based on the personal social network of customer managers, so the significance of the effect by organizational trust is uncertain. Actually, personal relationship can improve organizational trust, so we should know whether the personal relationship affect channel relation and behaviors directly or indirectly, through organizational trust. (Stephen A. Samaha, Robert W. Palmatier, \& Rajiv P. Dant, 2011, Keith G. Provan \& Steven J. Skinner, 1989)

In other word, we can know the mode of action of personal relationship to channel relation and behaviors by doing research on the relation among organizational trust and conflict, satisfaction and performance. If organizational trust has significant influence on conflict, satisfaction and performance, we can say that personal relationship's effect is indirect. If the results are not significant, then the influence of personal relationship on conflict, satisfaction and performance should be direct.

Based on the discussion above, we can have Hypothesis 4a, Hypothesis $4 \mathrm{~b}$ and Hypothesis 5:

$\mathrm{H}_{4 \mathrm{a}}$ : Organizational trust has negative effect on conflict. The stronger the organizational trust is, the weaker the conflict will be.

$H_{4 b}$ : Organizational trust has positive effect on satisfaction and performance. The stronger the organizational trust is, the higher the satisfaction and performance will be.

$\mathbf{H}_{5}$ : Personal relationship has positive effect on organizational trust. The better the personal relationship is, the stronger the organizational trust will be. 
Generally speaking, we can have a picture for all the hypotheses below:

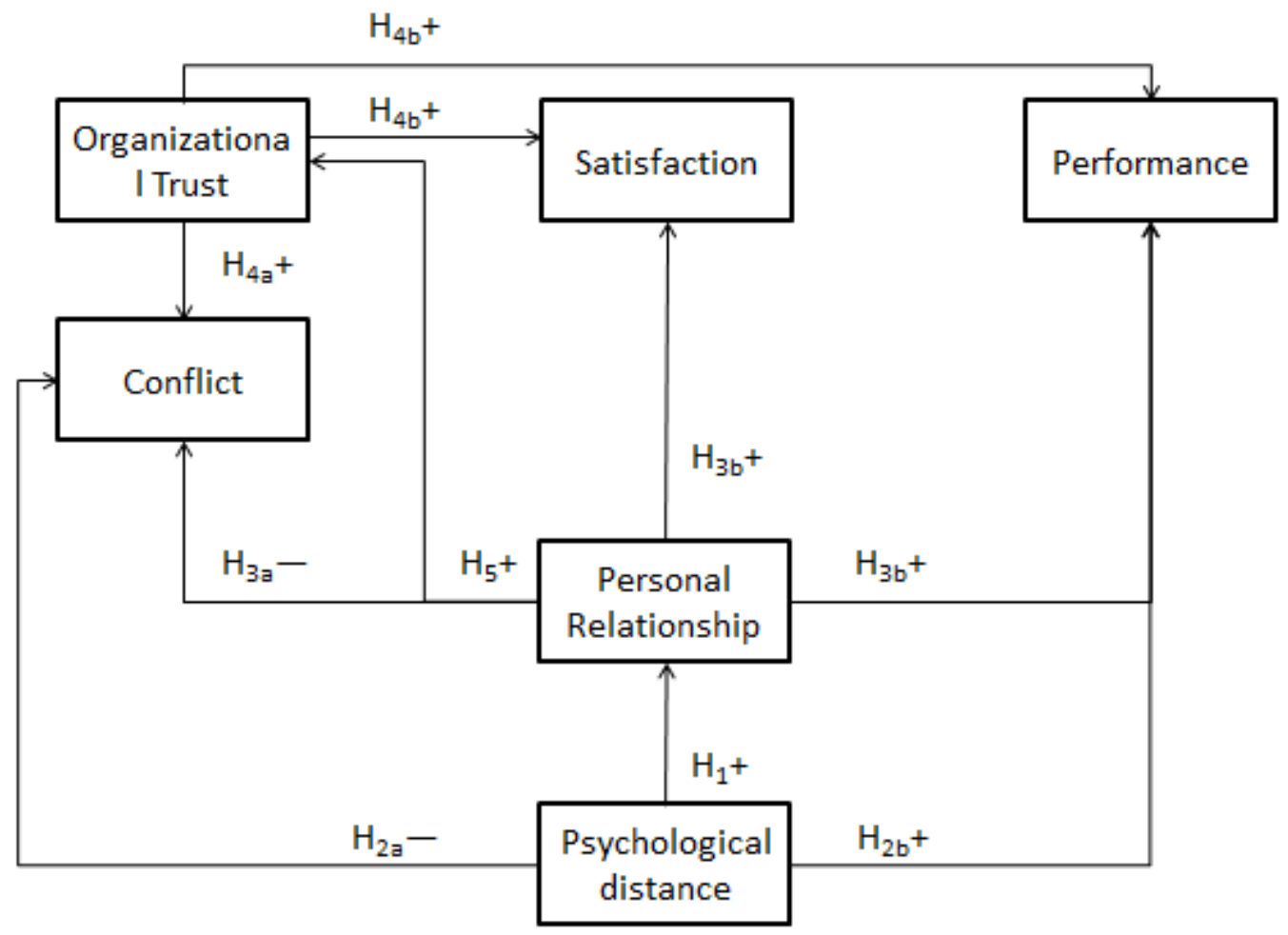

\section{Data Analyses and Results}

The data of our study come from 200 questionnaires of gas stations. We collected these data by sending questionnaires to the principals of all the gas stations. Every question is answered by a score from 1 to 5 . Score 1 means strongly disagreeing, and score 5 means strongly agreeing.

For psychological distance, we test it by two factors, calling value and strategy. About value, we ask questions such as "Whether the customer manager of Sinopec has similar commercial values with us?" About strategy, we ask questions such as "Whether do we have the same sales strategy as the customer manager of Sinopec?"

For personal relationship, we test it by two factors, calling the personal relation condition and the communication frequency. About the personal relation condition, we examine questions according to two elements, calling the fact of relationship and the willingness of contact. About the communication frequency, we examine questions according to two elements, calling the frequency of meeting and the frequency of calling.

For organizational trust, we test it by 5 dimensionalities. The reference questions are as below: 1 . Is Sinopec worth being trusted? 2. Do we believe that Sinopec will treat us sincerely? 3. Will we cooperate with Sinopec, even though the contract or policy is uncertain? 4. Do we always trust the explanation from Sinopec? 5. Does Sinopec ever get benefit by damaging our interests?

For conflict, we test it by 5 dimensionalities. The reference questions are about all kinds of conflict between Sinopec and the gas stations, such as the conflict in operation policy, promises keeping, pricing, promotion and risk taking.

For satisfaction, we test it by 5 dimensionalities. The reference questions are as below: 1. Generally speaking, do we feel satisfied of Sinopec? 2. Do we admire of the contribution Sinopec made to us? 3. Are we happy to cooperate with Sinopec? 4. Do we regret about cooperating with Sinopec? 5. Do we choose Sinopec again if we make the decision another time?

For performance, we test it by 4 dimensionalities. The reference questions are about capability, skills, operation ability and knowledge.

Then let's test all the hypotheses with quantitative method. 


\subsection{Test 1}

In this part, we will study the influence of psychological distance on each factor of personal relationship separately. There are two factors of psychological distance, calling value and strategy. The personal relationship consists of two factors, calling the personal relation condition and the communication frequency. And the personal relation condition can be separated into two parts, the fact of relationship and the willingness of contact. At the same time, the communication frequency consists of the frequency of meeting and the frequency of calling.

In a word, we are going to test the respective influence of value and strategy on 4 factors, calling the fact of relationship, the willingness of contact, the frequency of meeting or the frequency of calling.

Firstly, let's test the effect of value and strategy on two factors of the personal relation condition, calling the fact of relationship (fact), the willingness of contact (willingness).

\begin{tabular}{|c|c|c|c|c|c|c|}
\hline fact & Coef. & Std. Err. & $t$ & $P>|t|$ & [95\% Conf. & Interval] \\
\hline value & .327636 & .1218921 & 2.69 & 0.009 & .0855477 & .5697242 \\
\hline strategy & .1834695 & .1297275 & 1.41 & 0.161 & -.0741806 & .4411196 \\
\hline _cons & 1.892348 & .3966719 & 4.77 & 0.000 & 1.104523 & 2.680173 \\
\hline willingness & Coef. & Std. Err. & t & $P>|t|$ & [95\% Conf. & Interval] \\
\hline value & .1833671 & .0895878 & 2.05 & 0.044 & .005438 & .3612963 \\
\hline strategy & .3237261 & .0953467 & 3.40 & 0.001 & .1343594 & .5130929 \\
\hline _cons & 2.115613 & .2915445 & 7.26 & 0.000 & 1.53658 & 2.694646 \\
\hline
\end{tabular}

We can see that psychological distance has significant effect on personal relation condition.

Then let's see the effect of value and strategy on two factors of the communication frequency, calling the frequency of meeting (meet) or the frequency of calling (call).

\begin{tabular}{|c|c|c|c|c|c|c|}
\hline meet & Coef. & Std. Err. & t & $P>|t|$ & [95\% Conf. & Interval] \\
\hline value & .5705914 & .1337918 & 4.26 & 0.000 & .3048694 & .8363135 \\
\hline strategy & .0895848 & .1423922 & 0.63 & 0.531 & -.1932183 & .372388 \\
\hline _cons & .914832 & .4353969 & 2.10 & 0.038 & .0500961 & 1.779568 \\
\hline call & Coef. & Std. Err. & $t$ & $P>|t|$ & [95\% Conf. & Interval] \\
\hline value & .1533706 & .1250888 & 1.23 & 0.223 & -.0950666 & .4018078 \\
\hline strategy & .4073439 & .1331298 & 3.06 & 0.003 & .1429367 & .671751 \\
\hline$-^{\text {cons }}$ & 1.468965 & .407075 & 3.61 & 0.001 & .6604791 & 2.277451 \\
\hline
\end{tabular}

As we can see, value has positive effect on the frequency of meeting, and strategy has positive effect on the frequency of calling.

According to the analyses above, we can say that Hypothesis 1 is supported, that is psychological distance has positive effect on personal relationship. The closer the psychological distance is, the better the personal relationship will be. 


\subsection{Test 2}

First, let's study the influence of two factors of psychological distance, calling value and strategy on 5 dimensionalities of conflict.

\begin{tabular}{r|rrrrrr}
\hline conflict1 & Coef. & Std. Err. & $t$ & P $>|t|$ & [95\% Conf. Interval] \\
\hline value & .2874846 & .1711673 & 1.68 & 0.096 & -.0524684 & .6274376 \\
strategy & -.3658275 & .1821702 & -2.01 & 0.048 & -.7276333 & -.0040217 \\
_cons & 2.547834 & .5570275 & 4.57 & 0.000 & 1.44153 & 3.654139 \\
\hline
\end{tabular}

\begin{tabular}{r|rrrrrr}
\hline conflict2 & Coef. & Std. Err. & $t$ & P $>|t|$ & [95\% Conf. Interval] \\
\hline value & .287041 & .1794106 & 1.60 & 0.113 & -.0692839 & .6433659 \\
strategy & -.489733 & .1909434 & -2.56 & 0.012 & -.8689631 & -.110503 \\
_cons & 3.124164 & .5838535 & 5.35 & 0.000 & 1.96458 & 4.283747 \\
\hline
\end{tabular}

\begin{tabular}{r|rrrrrr}
\hline conflict3 & Coef. & Std. Err. & $t$ & P $>|t|$ & [95\% Conf. Interval] \\
\hline value & .1505821 & .1818093 & 0.83 & 0.410 & -.2105069 & .5116711 \\
strategy & -.3000624 & .1934963 & -1.55 & 0.124 & -.6843628 & .084238 \\
_cons & 2.805893 & .5916597 & 4.74 & 0.000 & 1.630806 & 3.98098 \\
\hline
\end{tabular}

\begin{tabular}{r|rrrrrr}
\hline conflict4 & Coef. & Std. Err. & $t$ & P $>|t|$ & [95\% Conf. Interval] \\
\hline value & .2888887 & .1869203 & 1.55 & 0.126 & -.0823511 & .6601284 \\
strategy & -.4187418 & .1989358 & -2.10 & 0.038 & -.8138455 & -.0236381 \\
_cons & 2.888682 & .6082922 & 4.75 & 0.000 & 1.680561 & 4.096803 \\
\hline
\end{tabular}

\begin{tabular}{r|rrrrrr}
\hline conflict5 & Coef. & Std. Err. & $t$ & P $>|t|$ & [95\% Conf. Interval] \\
\hline value & .3405062 & .1794014 & 1.90 & 0.061 & -.0158004 & .6968128 \\
strategy & -.5515786 & .1909336 & -2.89 & 0.005 & -.9307892 & -.1723679 \\
cons & 3.18345 & .5838236 & 5.45 & 0.000 & 2.023926 & 4.342974 \\
\hline
\end{tabular}

We can see that Hypothesis $2 \mathrm{a}$ is partly supported, that is psychological distance has negative effect on conflict. The closer the business values are, the weaker the conflict will be.

Then let's see the influence of two factors of psychological distance, calling value and strategy on 5 dimensionalities of satisfaction.

\begin{tabular}{r|rrrrrr}
\hline satisf1 & Coef. & Std. Err. & $t$ & P $>|t|$ & [95\% Conf. Interval] \\
\hline value & .1433328 & .1188878 & 1.21 & 0.231 & -.0927886 & .3794543 \\
strategy & .3950196 & .1265301 & 3.12 & 0.002 & .1437198 & .6463194 \\
_cons & 1.882837 & .3868951 & 4.87 & 0.000 & 1.11443 & 2.651244 \\
\hline
\end{tabular}




\begin{tabular}{r|rrrrrr}
\hline satisf2 & Coef. & Std. Err. & $t$ & P>|t| & [95\% Conf. Interval] \\
\hline value & .2921501 & .1061862 & 2.75 & 0.007 & .0812551 & .5030451 \\
strategy & .4427176 & .1130121 & 3.92 & 0.000 & .2182659 & .6671693 \\
_cons & 1.003359 & .3455605 & 2.90 & 0.005 & .317046 & 1.689672 \\
\hline
\end{tabular}

\begin{tabular}{r|rrrrrr}
\hline satisf3 & Coef. & Std. Err. & $t$ & P >|t| & [95\% Conf. Interval] \\
\hline value & .2610519 & .0939306 & 2.78 & 0.007 & .0744975 & .4476062 \\
strategy & .2241083 & .0999686 & 2.24 & 0.027 & .025562 & .4226547 \\
_cons & 2.304518 & .3056772 & 7.54 & 0.000 & 1.697417 & 2.91162 \\
\hline
\end{tabular}

\begin{tabular}{r|rrrrrr}
\hline satisf4 & Coef. & Std. Err. & $t$ & P $>|t|$ & [958 Conf. Interval] \\
\hline value & .2694419 & .0925475 & 2.91 & 0.005 & .0856347 & .4532491 \\
strategy & .2047834 & .0984966 & 2.08 & 0.040 & .0091608 & .4004061 \\
_cons & 2.317013 & .301176 & 7.69 & 0.000 & 1.718852 & 2.915175 \\
\hline
\end{tabular}

\begin{tabular}{r|rrrrrr}
\hline satisf5 & Coef. & Std. Err. & $t$ & P $>|t|$ & [95\% Conf. Interval] \\
\hline value & .2502925 & .09652 & 2.59 & 0.011 & .0585954 & .4419896 \\
strategy & .3014762 & .1027245 & 2.93 & 0.004 & .0974564 & .5054959 \\
cons & 2.029343 & .3141039 & 6.46 & 0.000 & 1.405506 & 2.653181 \\
\hline
\end{tabular}

Next, we can test the influence of two factors of psychological distance, calling value and strategy on 4 dimensionalities of performance.

\begin{tabular}{r|rrrrrr}
\hline performancel & Coef. & Std. Err. & $t$ & P $>|t|$ & [95\% Conf. Interval] \\
\hline value & .2139048 & .0737542 & 2.90 & 0.005 & .0674225 & .360387 \\
strategy & .2978394 & .0784953 & 3.79 & 0.000 & .141941 & .4537377 \\
_cons & 2.279046 & .2400174 & 9.50 & 0.000 & 1.802351 & 2.755741 \\
\hline
\end{tabular}

\begin{tabular}{r|rrrrrr}
\hline performance2 & Coef. & Std. Err. & $t$ & P>|t| & [95\% Conf. Interval] \\
\hline value & .2026872 & .072703 & 2.79 & 0.006 & .0582927 & .3470816 \\
strategy & .2362278 & .0773765 & 3.05 & 0.003 & .0825515 & .3899042 \\
_cons & 2.566233 & .2365964 & 10.85 & 0.000 & 2.096332 & 3.036134 \\
\hline
\end{tabular}




\begin{tabular}{r|rrrrrr}
\hline performance3 & Coef. & Std. Err. & $t$ & P>|t| & [95\% Conf. Interval] \\
\hline value & .1698095 & .0892909 & 1.90 & 0.060 & -.00753 & .3471489 \\
strategy & .3503052 & .0950307 & 3.69 & 0.000 & .1615661 & .5390443 \\
cons & 2.168054 & .2905782 & 7.46 & 0.000 & 1.590941 & 2.745168 \\
\hline
\end{tabular}

\begin{tabular}{r|rrrrrr}
\hline performance4 & Coef. & Std. Err. & $t$ & P $>|t|$ & [958 Conf. Interval] \\
\hline value & .2640062 & .0854382 & 3.09 & 0.003 & .0943184 & .4336939 \\
strategy & .2690178 & .0909304 & 2.96 & 0.004 & .0884222 & .4496133 \\
_cons & 2.125885 & .2780406 & 7.65 & 0.000 & 1.573672 & 2.678097 \\
\hline
\end{tabular}

As we can see, value and strategy both have positive effect on satisfaction and performance. So we can conclude that Hypothesis $2 b$ is supported, that is psychological distance has positive effect on satisfaction and performance. The closer the psychological distance is, the higher the satisfaction and performance will be. Here the influence of psychological distance on performance is indirect.

\subsection{Test 3}

In this part, we will study the influence of two factors of personal relationship, calling the personal relation condition and the communication frequency on 5 dimensionalities of conflict.

Because the personal relation condition and the communication frequency both have two elements, we can have the results of the regressions below:

\begin{tabular}{r|rrrrrr}
\hline conflict1 & Coef. & Std. Err. & $t$ & P $>|t|$ & [958 Conf. Interval] \\
\hline fact & .092529 & .2138151 & 0.43 & 0.666 & -.3322519 & .51731 \\
willingness & -.2315638 & .2847844 & -0.81 & 0.418 & -.7973378 & .3342101 \\
meet & .0200954 & .1926888 & 0.10 & 0.917 & -.3627146 & .4029054 \\
cal1 & .03595 & .1998606 & 0.18 & 0.858 & -.3611079 & .4330079 \\
_cons & 2.59988 & .7486705 & 3.47 & 0.001 & 1.112516 & 4.087245 \\
\hline
\end{tabular}

\begin{tabular}{|c|c|c|c|c|c|c|}
\hline conflict 2 & Coef. & Std. Err. & t & $P>|t|$ & [95응 Conf. & Interval] \\
\hline fact & .1584825 & .2264489 & 0.70 & 0.486 & -.2913978 & .6083629 \\
\hline willingness & -.2608497 & .3016117 & -0.86 & 0.389 & -.860054 & .3383546 \\
\hline meet & .144688 & .2040744 & 0.71 & 0.480 & -.2607414 & .5501175 \\
\hline call & -.1504564 & .2116699 & -0.71 & 0.479 & -.5709756 & .2700629 \\
\hline$-^{\operatorname{con} s}$ & 2.800143 & .7929078 & 3.53 & 0.001 & 1.224893 & 4.375392 \\
\hline conflict 3 & Coef. & Std. Err. & $t$ & $P>|t|$ & [95\% Conf. & Interval] \\
\hline fact & -.1048198 & .2254454 & -0.46 & 0.643 & -.5527063 & .3430668 \\
\hline willingness & .0697006 & .300275 & 0.23 & 0.817 & -.5268482 & .6662494 \\
\hline meet & .027325 & .20317 & 0.13 & 0.893 & -.3763076 & .4309577 \\
\hline $\operatorname{call}$ & -.0801388 & .2107318 & -0.38 & 0.705 & -.4987944 & .3385167 \\
\hline${ }_{-}^{\mathrm{cons}}$ & 2.520489 & .7893938 & 3.19 & 0.002 & .9522203 & 4.088758 \\
\hline
\end{tabular}




\begin{tabular}{|c|c|c|c|c|c|c|}
\hline conflict 4 & Coef. & Std. Err. & $t$ & $P>|t|$ & [95\% Conf. & Interval] \\
\hline fact & .0418284 & .2336286 & 0.18 & 0.858 & -.4223156 & .5059724 \\
\hline willingness & -.2023313 & .3111744 & -0.65 & 0.517 & -.8205336 & .4158711 \\
\hline meet & .1184306 & .2105447 & 0.56 & 0.575 & -.2998531 & .5367144 \\
\hline $\operatorname{call}$ & -.1211517 & .218381 & -0.55 & 0.580 & -.5550036 & .3127003 \\
\hline${ }_{-}$cons & 3.049204 & .8180473 & 3.73 & 0.000 & 1.42401 & 4.674397 \\
\hline conflict5 & Coef. & Std. Err. & t & $P>|t|$ & [95\% Conf. & Interval] \\
\hline fact & .1409999 & .2274436 & 0.62 & 0.537 & -.3108565 & .5928562 \\
\hline willingness & -.3427134 & .3029365 & -1.13 & 0.261 & -.9445496 & .2591228 \\
\hline meet & .1375927 & .2049708 & 0.67 & 0.504 & -.2696175 & .5448028 \\
\hline call & -.1596501 & .2125996 & -0.75 & 0.455 & -.5820164 & .2627161 \\
\hline${ }^{\operatorname{con} s}$ & 3.283596 & .7963905 & 4.12 & 0.000 & 1.701427 & 4.865764 \\
\hline
\end{tabular}

As we can see, personal relationship does not have significant effect on conflict, so Hypothesis $3 \mathrm{a}$ is refused.

Then let's see the influence of two factors of personal relationship, calling the personal relation condition and the communication frequency on 5 dimensionalities of satisfaction.

\begin{tabular}{|c|c|c|c|c|c|c|}
\hline satisf2 & Coef. & Std. Err. & $t$ & $P>|t|$ & [95\% Conf. & Interval] \\
\hline fact & -.0127197 & .1500997 & -0.08 & 0.933 & -.3109191 & .2854796 \\
\hline willingness & .5092147 & .1999207 & 2.55 & 0.013 & .1120373 & .9063922 \\
\hline meet & .0950924 & .135269 & 0.70 & 0.484 & -.173643 & .3638279 \\
\hline call & .0976455 & .1403036 & 0.70 & 0.488 & -.181092 & .3763831 \\
\hline${ }_{-}^{\operatorname{cons}}$ & 1.154116 & .5255721 & 2.20 & 0.031 & .1099756 & 2.198257 \\
\hline satisf3 & Coef. & Std. Err. & $t$ & $P>|t|$ & [95\% Conf. & Interval] \\
\hline fact & .198383 & .1230708 & 1.61 & 0.110 & -.0461186 & .4428846 \\
\hline willingness & .019931 & .1639203 & 0.12 & 0.903 & -.3057254 & .3455874 \\
\hline meet & .0785018 & .1109106 & 0.71 & 0.481 & -.1418416 & .2988451 \\
\hline call & .1531314 & .1150386 & 1.33 & 0.187 & -.0754129 & .3816757 \\
\hline$-^{\operatorname{cons}}$ & 2.51237 & .4309306 & 5.83 & 0.000 & 1.656251 & 3.368489 \\
\hline satisf 4 & Coef. & Std. Err. & $t$ & $P>|t|$ & [95\% Conf. & Interval] \\
\hline fact & .1349074 & .1160981 & 1.16 & 0.248 & -.0957418 & .3655565 \\
\hline willingness & .2321871 & .1546333 & 1.50 & 0.137 & -.0750189 & .5393932 \\
\hline meet & .1380311 & .1046269 & 1.32 & 0.190 & -.0698285 & .3458907 \\
\hline call & .0193032 & .108521 & 0.18 & 0.859 & -.1962928 & .2348992 \\
\hline${ }_{-}^{\operatorname{cons}}$ & 2.140833 & .4065159 & 5.27 & 0.000 & 1.333218 & 2.948448 \\
\hline
\end{tabular}




\begin{tabular}{r|rrrrrr}
\hline satisf5 & Coef. & Std. Err. & $t$ & $\mathrm{P}>|\mathrm{t}|$ & [95\% Conf. Interval] \\
\hline fact & .2639671 & .1230742 & 2.14 & 0.035 & .0194587 & .5084755 \\
willingness & .1745605 & .1639249 & 1.06 & 0.290 & -.151105 & .5002259 \\
meet & .0875709 & .1109137 & 0.79 & 0.432 & -.1327786 & .3079204 \\
call & .0549151 & .1150418 & 0.48 & 0.634 & -.1736356 & .2834658 \\
cons & 1.941619 & .4309426 & 4.51 & 0.000 & 1.085476 & 2.797761 \\
\hline
\end{tabular}

We can see that personal relationship does not have a significant effect on satisfaction.

Next, we can test the influence of two factors of personal relationship, calling the personal relation condition and the communication frequency on 4 dimensionalities of performance.

\begin{tabular}{|c|c|c|c|c|c|c|}
\hline performancel & Coef. & Std. Err. & $t$ & $P>|t|$ & [95\% Conf. & Interval] \\
\hline fact & .1551544 & .0936582 & 1.66 & 0.101 & -.030914 & .3412227 \\
\hline willingness & .3396853 & .1247452 & 2.72 & 0.008 & .0918573 & .5875134 \\
\hline meet & .0818964 & .0844042 & 0.97 & 0.335 & -.0857873 & .2495801 \\
\hline call & -.0156576 & .0875457 & -0.18 & 0.858 & -.1895823 & .1582671 \\
\hline - cons $^{\text {cons }}$ & 2.060099 & .3279429 & 6.28 & 0.000 & 1.408584 & 2.711615 \\
\hline performance 2 & Coef. & Std. Err. & $t$ & $P>|t|$ & [95\% Conf. & Interval] \\
\hline fact & .2032875 & .0822561 & 2.47 & 0.015 & .0398714 & .3667036 \\
\hline willingness & .20499 & .1095585 & 1.87 & 0.065 & -.0126671 & .422647 \\
\hline meet & .0954735 & .0741287 & 1.29 & 0.201 & -.0517961 & .2427431 \\
\hline $\operatorname{call}$ & .0685547 & .0768877 & 0.89 & 0.375 & -.0841961 & .2213056 \\
\hline$-^{\operatorname{cons}}$ & 2.069568 & .2880186 & 7.19 & 0.000 & 1.497369 & 2.641767 \\
\hline performance 3 & Coef. & Std. Err. & $t$ & $P>|t|$ & [95용 Conf. & Interval] \\
\hline fact & .0730788 & .1141045 & 0.64 & 0.524 & -.1536097 & .2997673 \\
\hline willingness & .4230609 & .151978 & 2.78 & 0.007 & .1211302 & .7249917 \\
\hline meet & -.0003605 & .1028303 & -0.00 & 0.997 & -.2046508 & .2039298 \\
\hline call & .0960322 & .1066575 & 0.90 & 0.370 & -.1158617 & .307926 \\
\hline - cons $^{\text {cons }}$ & 1.838357 & .3995353 & 4.60 & 0.000 & 1.04461 & 2.632103 \\
\hline performance 4 & Coef. & Std. Err. & $t$ & $P>|t|$ & [95\% Conf. & Interval] \\
\hline fact & .3086588 & .1100146 & 2.81 & 0.006 & .0900956 & .527222 \\
\hline willingness & .1525226 & .1465306 & 1.04 & 0.301 & -.1385859 & .4436311 \\
\hline meet & .0361516 & .0991445 & 0.36 & 0.716 & -.1608162 & .2331194 \\
\hline call & .0463965 & .1028346 & 0.45 & 0.653 & -.1579023 & .2506953 \\
\hline - cons $^{\text {cons }}$ & 2.08946 & .3852145 & 5.42 & 0.000 & 1.324164 & 2.854755 \\
\hline
\end{tabular}

We can see that the personal relation condition has significant effect on performance, but the communication frequency does not have significant effect on performance.

Generally speaking, Hypothesis $3 \mathrm{~b}$ is partly supported, that is personal relationship does not have significant influence on satisfaction, but the personal relation condition has significant influence on performance, meaning that personal relationship may have effect on performance. 


\subsection{Test 4}

In this part, we will study the influence of 5 elements of organizational trust on 5 dimensionalities of conflict.

\begin{tabular}{r|rrrrrr}
\hline conflict1 & Coef. & Std. Err. & $t$ & $\mathrm{P}>|\mathrm{t}|$ & [95\% Conf. Interval] \\
\hline CT1 & -.1352913 & .176293 & -0.77 & 0.445 & -.4855817 & .2149992 \\
CT2 & -.1549765 & .2092745 & -0.74 & 0.461 & -.5708005 & .2608475 \\
CT3 & .3560126 & .1709457 & 2.08 & 0.040 & .0163471 & .695678 \\
CT4 & -.0089387 & .1784538 & -0.05 & 0.960 & -.3635225 & .3456451 \\
CT5 & -.3218586 & .1795909 & -1.79 & 0.077 & -.678702 & .0349847 \\
Cons & 3.275066 & .6621426 & 4.95 & 0.000 & 1.959403 & 4.590729 \\
\hline & & & & & & \\
\hline \multirow{2}{*}{ conflict2 } & Coef. & Std. Err. & $t$ & P>|t| & {$[95 \%$ Conf. } & Interval] \\
\hline CT1 & .0490169 & .1852163 & 0.26 & 0.792 & -.3190039 & .4170376 \\
CT2 & -.2929123 & .2198672 & -1.33 & 0.186 & -.7297837 & .1439591 \\
CT3 & .1322758 & .1795983 & 0.74 & 0.463 & -.2245822 & .4891338 \\
CT4 & -.0979653 & .1874864 & -0.52 & 0.603 & -.4704968 & .2745661 \\
CT5 & -.2457353 & .1886811 & -1.30 & 0.196 & -.6206407 & .12917 \\
Cons & 4.061859 & .6956576 & 5.84 & 0.000 & 2.679603 & 5.444116 \\
\hline
\end{tabular}

\begin{tabular}{|c|c|c|c|c|c|c|}
\hline conflict 3 & Coef. & Std. Err. & $t$ & $P>|t|$ & [95\% Conf. & Interval] \\
\hline CT1 & -.174658 & .1910919 & -0.91 & 0.363 & -.5543535 & .2050376 \\
\hline $\mathrm{CT} 2$ & -.1138842 & .2268421 & -0.50 & 0.617 & -.5646146 & .3368461 \\
\hline CT3 & .2377845 & .1852957 & 1.28 & 0.203 & -.1303941 & .6059632 \\
\hline $\mathrm{CT} 4$ & -.1059163 & .1934341 & -0.55 & 0.585 & -.4902656 & .2784331 \\
\hline CT5 & -.0877298 & .1946667 & -0.45 & 0.653 & -.4745283 & .2990688 \\
\hline${ }_{-}^{\operatorname{con} s}$ & 3.22681 & .7177261 & 4.50 & 0.000 & 1.800703 & 4.652916 \\
\hline conflict 4 & Coef. & Std. Err. & $t$ & $P>|t|$ & [95응 Conf. & Interval] \\
\hline CT1 & -.181845 & .1984408 & -0.92 & 0.362 & -.5761426 & .2124527 \\
\hline $\mathrm{CT} 2$ & -.0771045 & .2355658 & -0.33 & 0.744 & -.5451688 & .3909597 \\
\hline CT3 & .1649725 & .1924217 & 0.86 & 0.394 & -.2173654 & .5473103 \\
\hline CT 4 & .0374324 & .200873 & 0.19 & 0.853 & -.3616981 & .4365628 \\
\hline CT5 & -.2184608 & .2021531 & -1.08 & 0.283 & -.6201346 & .183213 \\
\hline - cons $^{\text {cons }}$ & 3.477159 & .745328 & 4.67 & 0.000 & 1.996208 & 4.958109 \\
\hline conflict 5 & Coef. & Std. Err. & $t$ & $P>|t|$ & [95\% Conf. & Interval] \\
\hline CT1 & -.1717019 & .1899055 & -0.90 & 0.368 & -.5490401 & .2056362 \\
\hline $\mathrm{CT} 2$ & -.0252017 & .2254337 & -0.11 & 0.911 & -.4731336 & .4227303 \\
\hline CT3 & -.0853803 & .1841453 & -0.46 & 0.644 & -.451273 & .2805125 \\
\hline CT 4 & .0513673 & .1922331 & 0.27 & 0.790 & -.3305958 & .4333304 \\
\hline CT5 & -.2206927 & .1934581 & -1.14 & 0.257 & -.6050898 & .1637043 \\
\hline _cons & 4.123752 & .71327 & 5.78 & 0.000 & 2.7065 & 5.541004 \\
\hline
\end{tabular}

As we can see, all of the 5 elements of organizational trust do not have significant effect on conflict, so Hypothesis $4 \mathrm{a}$ is refused. 
Then we can see the influence of 5 elements of organizational trust on 5 dimensionalities of satisfaction.

\begin{tabular}{r|rrrrrr}
\hline satisf1 & Coef. & Std. Err. & $t$ & P $>|t|$ & [958 Conf. Interval] \\
\hline CT1 & .1411588 & .1247239 & 1.13 & 0.261 & -.1066649 & .3889825 \\
CT2 & .2349973 & .1480577 & 1.59 & 0.116 & -.0591902 & .5291847 \\
CT3 & .056344 & .1209408 & 0.47 & 0.642 & -.1839628 & .2966507 \\
CT4 & .1417894 & .1262526 & 1.12 & 0.264 & -.1090718 & .3926506 \\
CT5 & .0541656 & .1270571 & 0.43 & 0.671 & -.1982942 & .3066254 \\
_cons & 1.456768 & .4684531 & 3.11 & 0.003 & .5259613 & 2.387574 \\
\hline
\end{tabular}

\begin{tabular}{r|rrrrrr}
\hline satisf2 & Coef. & Std. Err. & $t$ & P $>|t|$ & [95\% Conf. Interval] \\
\hline CT1 & .3407237 & .1103471 & 3.09 & 0.003 & .1214663 & .5599811 \\
CT2 & .0357497 & .1309913 & 0.27 & 0.786 & -.2245272 & .2960266 \\
CT3 & -.055277 & .1070001 & -0.52 & 0.607 & -.2678839 & .15733 \\
CT4 & .2941462 & .1116996 & 2.63 & 0.010 & .0722014 & .516091 \\
CT5 & .189045 & .1124114 & 1.68 & 0.096 & -.034314 & .4124041 \\
Cons & .6432513 & .4144551 & 1.55 & 0.124 & -.1802623 & 1.466765 \\
\hline
\end{tabular}

\begin{tabular}{r|rrrrrr}
\hline satisf3 & Coef. & Std. Err. & $t$ & P>|t| & [95\% Conf. Interval] \\
\hline CT1 & .0443438 & .0945404 & 0.47 & 0.640 & -.143506 & .2321935 \\
CT2 & .239031 & .1122274 & 2.13 & 0.036 & .0160377 & .4620244 \\
CT3 & .003745 & .0916728 & 0.04 & 0.968 & -.1784069 & .1858969 \\
CT4 & .2259346 & .0956992 & 2.36 & 0.020 & .0357824 & .4160868 \\
CT5 & .0571498 & .096309 & 0.59 & 0.554 & -.1342141 & .2485137 \\
_cons & 1.93058 & .3550863 & 5.44 & 0.000 & 1.225031 & 2.636129 \\
\hline
\end{tabular}

\begin{tabular}{r|rrrrrr}
\hline satisf4 & Coef. & Std. Err. & $t$ & P $>|t|$ & [95\% Conf. Interval] \\
\hline CT1 & .1397287 & .0854122 & 1.64 & 0.105 & -.0299835 & .3094408 \\
CT2 & .1380794 & .1013914 & 1.36 & 0.177 & -.0633832 & .3395419 \\
CT3 & .061894 & .0828215 & 0.75 & 0.457 & -.1026705 & .2264585 \\
CT4 & .1547647 & .0864591 & 1.79 & 0.077 & -.0170276 & .326557 \\
CT5 & .1533574 & .08701 & 1.76 & 0.081 & -.0195296 & .3262444 \\
_cons & 1.587 & .3208014 & 4.95 & 0.000 & .9495744 & 2.224426 \\
\hline
\end{tabular}

\begin{tabular}{r|rrrrrr}
\hline satisf5 & Coef. & Std. Err. & $t$ & P>|t] & [95\% Conf. Interval] \\
\hline CT1 & .4208166 & .0984634 & 4.27 & 0.000 & .2251719 & .6164613 \\
CT2 & -.0613711 & .1168843 & -0.53 & 0.601 & -.2936176 & .1708755 \\
CT3 & -.0239303 & .0954768 & -0.25 & 0.803 & -.2136407 & .1657801 \\
CT4 & .1025527 & .0996702 & 1.03 & 0.306 & -.0954899 & .3005953 \\
CT5 & .1770841 & .1003054 & 1.77 & 0.081 & -.0222205 & .3763887 \\
Cons & 1.658785 & .3698207 & 4.49 & 0.000 & .9239591 & 2.393611 \\
\hline
\end{tabular}

We cannot see significant effect of organizational trust on satisfaction. 
Next, let's test the influence of 5 elements of organizational trust on 4 dimensionalities of performance.

\begin{tabular}{r|rrrrrr}
\hline performance1 & Coef. & Std. Err. & $t$ & P >|t| & [95\% Conf. Interval] \\
\hline CT1 & .2896502 & .0861693 & 3.36 & 0.001 & .1184336 & .4608668 \\
CT2 & -.039043 & .1022902 & -0.38 & 0.704 & -.2422914 & .1642054 \\
CT3 & .1061021 & .0835556 & 1.27 & 0.207 & -.0599211 & .2721254 \\
CT4 & .1848393 & .0872255 & 2.12 & 0.037 & .0115242 & .3581544 \\
CT5 & -.0554091 & .0877813 & -0.63 & 0.530 & -.2298286 & .1190105 \\
C Cons & 2.272783 & .3236451 & 7.02 & 0.000 & 1.629707 & 2.915859 \\
\hline
\end{tabular}

\begin{tabular}{r|rrrrrr}
\hline performance2 & Coef. & Std. Err. & $t$ & P $>|t|$ & [95\% Conf. Interval] \\
\hline CT1 & .2291721 & .0834872 & 2.74 & 0.007 & .0632848 & .3950594 \\
CT2 & -.0276245 & .0991063 & -0.28 & 0.781 & -.2245466 & .1692976 \\
CT3 & .0344694 & .0809549 & 0.43 & 0.671 & -.1263862 & .195325 \\
CT4 & .1889257 & .0845105 & 2.24 & 0.028 & .0210051 & .3568462 \\
CT5 & -.016573 & .085049 & -0.19 & 0.846 & -.1855636 & .1524176 \\
_cons & 2.607229 & .3135714 & 8.31 & 0.000 & 1.984169 & 3.230289 \\
\hline
\end{tabular}

\begin{tabular}{r|rrrrrr}
\hline performance3 & Coef. & Std. Err. & $t$ & P $>|t|$ & [95\% Conf. Interval] \\
\hline CT1 & .3475261 & .0966098 & 3.60 & 0.001 & .1555644 & .5394877 \\
CT2 & -.227976 & .1146839 & -1.99 & 0.050 & -.4558506 & -.0001015 \\
CT3 & .1911323 & .0936795 & 2.04 & 0.044 & .0049932 & .3772714 \\
CT4 & .1069252 & .0977939 & 1.09 & 0.277 & -.0873893 & .3012396 \\
CT5 & .0800364 & .0984171 & 0.81 & 0.418 & -.1155163 & .2755891 \\
_cons & 2.184585 & .3628589 & 6.02 & 0.000 & 1.463592 & 2.905578 \\
\hline
\end{tabular}

\begin{tabular}{r|rrrrrr}
\hline performance4 & Coef. & Std. Err. & $t$ & P $>|t|$ & [95\% Conf. Interval] \\
\hline CT1 & .2705488 & .1005705 & 2.69 & 0.009 & .0707173 & .4703802 \\
CT2 & -.1613251 & .1193856 & -1.35 & 0.180 & -.3985417 & .0758916 \\
CT3 & -.0025107 & .09752 & -0.03 & 0.980 & -.1962809 & .1912595 \\
CT4 & .2283624 & .1018032 & 2.24 & 0.027 & .0260817 & .4306432 \\
CT5 & .0931366 & .1024519 & 0.91 & 0.366 & -.1104331 & .2967064 \\
_cons & 2.486731 & .3777349 & 6.58 & 0.000 & 1.736179 & 3.237282 \\
\hline
\end{tabular}

We cannot see significant effect of organizational trust on performance.

Generally speaking, we can say that Hypothesis $4 \mathrm{~b}$ is refused, that is organizational trust does not have significant influence on satisfaction or performance.

4.5 Test 5

In this part, we will study the influence of two factors of personal relationship, calling the personal relation condition and the communication frequency on 5 dimensionalities of organizational trust. 
Because the personal relation condition and the communication frequency both have two elements, we can have the results of the regressions below:

\begin{tabular}{|c|c|c|c|c|c|c|}
\hline CT1 & Coef. & Std. Err. & $t$ & $P>|t|$ & [95\% Conf. & Interval] \\
\hline fact & -.3861454 & .1447799 & -2.67 & 0.009 & -.6737758 & -.0985149 \\
\hline willingness & .7082709 & .1928351 & 3.67 & 0.000 & .3251703 & 1.091371 \\
\hline meet & .049734 & .1304747 & 0.38 & 0.704 & -.2094768 & .3089448 \\
\hline call & .1038859 & .1353309 & 0.77 & 0.445 & -.1649726 & .3727443 \\
\hline _cons & 2.364143 & .5069446 & 4.66 & 0.000 & 1.357009 & 3.371277 \\
\hline $\mathrm{CT} 2$ & Coef. & Std. Err. & t & $P>|t|$ & [95\% Conf. & Interval] \\
\hline fact & -.1785557 & .152022 & -1.17 & 0.243 & -.4805739 & .1234625 \\
\hline willingness & .414611 & .202481 & 2.05 & 0.044 & .0123472 & .8168749 \\
\hline meet & -.0405921 & .1370013 & -0.30 & 0.768 & -.312769 & .2315849 \\
\hline call & .181148 & .1421004 & 1.27 & 0.206 & -.1011591 & .4634552 \\
\hline - cons $^{\text {cons }}$ & 2.572247 & .5323028 & 4.83 & 0.000 & 1.514735 & 3.62976 \\
\hline CT3 & Coef. & Std. Err. & t & $P>|t|$ & [95옹 Conf. & - Interval] \\
\hline fact & -.1882197 & .1649649 & -1.14 & 0.257 & -.5159512 & .1395117 \\
\hline willingness & .5011099 & .2197199 & 2.28 & 0.025 & .064598 & .9376218 \\
\hline meet & -.0176854 & .1486653 & -0.12 & 0.906 & -.3130351 & .2776642 \\
\hline call & .3057113 & .1541985 & 1.98 & 0.050 & -.000631 & .6120536 \\
\hline$-^{\operatorname{cons}}$ & 1.528033 & .5776221 & 2.65 & 0.010 & .3804862 & 2.675581 \\
\hline CT 4 & Coef. & Std. Err. & $t$ & $P>|t|$ & [95\% Conf. & - Interval] \\
\hline fact & .179166 & .1566455 & 1.14 & 0.256 & -.1320378 & .4903697 \\
\hline willingness & .3914497 & .2086392 & 1.88 & 0.064 & -.0230485 & .805948 \\
\hline meet & .1845597 & .141168 & 1.31 & 0.194 & -.0958953 & .4650146 \\
\hline call & -.0622472 & .1464222 & -0.43 & 0.672 & -.3531404 & .228646 \\
\hline - cons $^{\text {cons }}$ & 1.126757 & .5484922 & 2.05 & 0.043 & .0370818 & 2.216433 \\
\hline CT5 & coef. & std. Err. & $t$ & $P>|t|$ & [95\% conf. & Interva1] \\
\hline $\begin{array}{r}\text { fact } \\
\text { wi11ingness } \\
\text { meet } \\
\text { cal1 } \\
\text { _cons }\end{array}$ & $\begin{array}{r}-.0871691 \\
.6432939 \\
-.0649666 \\
.307948 \\
.5289047\end{array}$ & $\begin{array}{r}.1689012 \\
.2249628 \\
.1522128 \\
.157878 \\
.5914053\end{array}$ & $\begin{array}{r}-0.52 \\
2.86 \\
-0.43 \\
1.95 \\
0.89\end{array}$ & $\begin{array}{l}0.607 \\
0.005 \\
0.671 \\
0.054 \\
0.374\end{array}$ & $\begin{array}{r}-.4227209 \\
.196366 \\
-.3673638 \\
-.0057043 \\
-.6460252 \\
\end{array}$ & $\begin{array}{r}.2483826 \\
1.090222 \\
.2374307 \\
.6216002 \\
1.703835\end{array}$ \\
\hline
\end{tabular}

We can see that the willingness of contact has significant effect on organizational trust, but other factors do not have significant effect on it. As a result, we can say that Hypothesis 5 is partly supported, that is personal relationship may have positive effect on organizational trust. The better the personal relationship is, the stronger the organizational trust will be.

\section{Conclusion and Discussions}

We collect the data from 200 gas station of Sinopec, to study the influence of psychological distance and personal relationship of channel members on conflict, satisfaction and performance. 
The result of our study show up several results below:

1. Psychological distance has positive influence on personal relationship, satisfaction and performance. The closer the psychological distance is, the better the personal relationship will be, and the higher the satisfaction and performance will be. Psychological distance has negative influence on conflict. The closer the psychological distance is, the weaker the conflict will be.

Psychological distance refers to the differences of values and ways of thinking. The effect of value and strategy on personal relationship is not surprising, which is supported by the reference. Those who have closer psychological distance will be easier to understand each other and cooperated with each other, leading to higher satisfaction and performance. Conflict has nothing to do with values, but has some relation with operation strategy, which may help channel members reach an agreement and reduce conflict. (Federico de Gregorio, Yunjae Cheong, \& Kihan Kim, 2012)

2. One part of personal relationship, calling the personal relation condition has positive influence on performance. The better the personal relation condition is, the higher the performance will be.

The impact of personal connection is quite obvious in China's business environment and traditional culture. Sometimes, the distributors can hardly know whether the suppliers are reliable or not, but they can judge this from the customer managers. Good personal relationship condition will give them confidence of the organization the boundary-spanners belonging to, so that the performance will be higher. For the distributors, the fact of relationship and the willingness of contact are very important, because they show that the distributors do not only try to cooperate with suppliers, but also be willing to do that. However, the communication frequency doesn't affect the channel relationship and operation process, so it will not have significant effect on performance.

3. One element of personal relationship, calling the willingness of contact has positive influence on organizational trust. The higher the willingness of contact is, the higher the organizational trust will be.

Sometimes, the willingness to communicate is more important than the behavior of communication, because willingness reflects the trust and feeling of closeness but the behavior may come from judgment of reality. The behavior of trust is perhaps to maintain relationship, rather than to show their real trust from heart. In another word, it is easier to build a trust relationship when someone or some organizations have willingness of interaction of others. This description has the same viewpoint as our research, that the principal of the gas station may improve the organizational trust on Sinopec because of the good feeling of the customer manager. (Robert M. Morgan \& Shelby D. Hunt, 1994)

4. Organizational trust does not have significant influence on conflict, satisfaction or performance.

Many previous references mentioned the improvement effect of organizational trust on channel relationship. However, we cannot see that in our study. The reason could be very complicated. The particularity of China business environment will strengthen the influence of personal trust, which is the trust between distributor and the customer manager in our research. Personal relationship is more simple and practical, especially for those small distributors. In China, the trust of distributors on the salesmen from suppliers will be more significant on their decisions and behaviors than the trust on the organization of suppliers. The reason may be that small distributors usually can hardly know about the large suppliers, so they choose to believe in persons. In conclusion, the effect of organizational trust on conflict, satisfaction and performance can be easily replaced by the personal relationship, when we are discussing China's business environment, with small players of distributors. (Don Y. Lee \& Philip L. Dawes, 2005)

Here we can see some implications for the suppliers in China. Not as usual, we cannot see significant effect of organizational trust on conflict satisfaction or performance. The reason may be that in the cooperation between little distributors and large suppliers in China, organizational relationship is usually replaced by personal relationship. As a result, the suppliers should not ignore the importance of boundary-spanners, like customer managers or salesmen. Personal relationship can lead to organizational trust, by the hard work of staffs in the long term. This conclusion conforms to the reality in China's business environment.

However, the advantage of personal relationship can be the disadvantage during some situation. For example, if one day the salesmen or customer managers leave the company, the suppliers may face the risk of losing some of distributors.

On the other hand, our study still has some shortages, which can be improved during future research. First, we can pay more attention to discussing the differences of every influence factor, which will be more interesting. Second, if we can have more diversified data, the result will be more convincing. Third, we cannot find much theory support for 
psychological distance, which should be added to in the future. Fourth, we should try to find more details to explain the unusual effect of organizational trust in our research.

\section{References}

Anderson \& Narus. (1990). A Model of Distributor Firm and Manufacturer Firm Working Partnerships. Journal of Marketing, 1 January 1990, 54(1), 42-58. http://dx.doi.org/10.2307/1252172

Bert Rosenbloom. (1973). Conflict and Channel Efficiency: Some Conceptual Models for the Decision maker. Journal of Marketing, 37 (July 1973), 26-30. http://dx.doi.org/10.2307/1249943

Coleman. (1990). Introduction, Neurobiology of $\quad$ Aging, $\quad 11(3), \quad$ 251-251. http://dx.doi.org/10.1016/0197-4580(90)90555-E

Dant et al. (2006). Stedman's Medical Dictionary. Wolters Kluwer Health, Lippincott Williams \& Wilkins.

Dickey et al. (2007). Improving Staff Influenza Vaccination Campaign (IVC) Participation through Electronic Intranet Tracking at a University Based Hospital. American Journal of Infection Control, 35(5), pp.E112-E112. http://dx.doi.org/10.1016/j.ajic.2007.04.128

Don Y. Lee \& Philip L. Dawes. (2005). Guanxi, Trust, and Long-Term Orientation in Chinese Business Markets. Journal of International Marketing, 13, 2, 28-56. http://dx.doi.org/10.1509/jimk.13.2.28.64860

Federico de Gregorio, Yunjae Cheong, \& Kihan Kim. (2012). Intra-organizational Conflict Within Advertising Agencies. Journal of Advertising, 41(3), (Fall 2012), 19-34..

Fulop \& Forward. (1997). Insights into Franchising: A Review of Empirical and Theoretical Perspectives. The Service Industries Journal, 01 October 1997, 17(4), 603-625. http://dx.doi.org/10.1080/02642069700000037

Garg \& Rasheed. (2006). An Explanation of International Franchisors' Preference for Multi-unit Franchising. International Journal of Entrepreneurship, Annual, 10, 1(20).

Gaski \& Nevin. (1985). The Differential Effects of Exercised and Unexercised Power Sources in a Marketing Channel. Journal of Marketing Research, 22(2), (May, 1985), 130-142. http://dx.doi.org/10.2307/3151359

Gaski. (1984). The Theory of Power and Conflict in Channels of Distribution. Journal of Marketing, 1 July, 48(3), 9-29. http://dx.doi.org/10.2307/1251326

Graham R. Massey \& Philip L. Dawes. (2007). Personal Characteristics, Trust, Conflict, and Effectiveness in Marketing/Sales Working Relationships. European Journal of Marketing, 41(9/10), 1117-1145. http://dx.doi.org/10.1108/03090560710773372

Grünhagen \& Dorsch. (2003). Does the Franchisor Provide Value to Franchisees? Past, Current, and Future Value Assessments of Two Franchisee Types. Journal of Small Business Management, 41(4), 366-384. http://dx.doi.org/10.1111/1540-627X.00088

Jan B. Heide. (1994). Inter-organizational Governance in Marketing Channels. Journal of Marketing, 56, (January 1994), 71-85. http://dx.doi.org/10.2307/1252252

Keith G. Provan \& Steven J. Skinner. (1989). Inter-organizational Dependence and Control as Predictors of Opportunism in Dealer-Supplier Relations. The Academy of Management Journal, 32(1), (Mar., 1989), 202-212. http://dx.doi.org/10.2307/256427

Mark A.P. Davies, Walfried Lassar, Chris Manolis, Melvin Prince, \& Robert D. Winsor. (2011). A Model of Trust and Compliance in Franchise Relationships. Journal of Business Venturing, 26, 321-340. http://dx.doi.org/10.1016/j.jbusvent.2009.09.005

Mayer et al. (1995). Mayer, Thomas: Doing economic research: Aldershot, Elgar. The Manchester School of Economic and Social Studies, 63(4), 445.

Robert M. Morgan \& Shelby D. Hunt. (1994). The Commitment-Trust Theory of Relationship Marketing. Journal of Marketing, 58, (July 1994), 20-38. http://dx.doi.org/10.2307/1252308

Shane \& Cable. (1997). A Prisoner's Dilemma Approach to Entrepreneur-Venture Capitalist Relationships. The Academy of Management Review, 22(1), (Jan., 1997), 142-176.

Stephen A. Samaha, Robert W. Palmatier, \& Rajiv P. Dant. (2011). Poisoning Relationships: Perceived Unfairness in Channels of Distribution. Journal of Marketing, 75, (May 2011), 99-117. http://dx.doi.org/10.1509/jmkg.75.3.99 